Office of Naval Research

Department of the Navy

Contract Nonr-220(28)

\title{
EFFECTS OF THERMAL CONDUCTION IN SONOLUMINESCENCE
}

\author{
by \\ Robert Hickling
}

\begin{abstract}
Engineering Division CALIFORNIA INSTITUTE OF TECHNOLOGY

Pasadena, California
\end{abstract}

Report No. $85 \cdot 21$

November, 1962
Approved by:

M. S. Plesset 


\title{
Office of Naval Research \\ Department of the Navy \\ Contract Nonr-220(28)
}

\section{EFFECTS OF THERMAL CONDUCTION IN SONOLUMINESCENCE}

\author{
Robert Hickling
}

\section{Reproduction in whole or in part is permitted for any purpose of the United States Government}

Engineering Division

\section{California Institute of Technology}

Pasadena, California

Report No. 85-21

November, 1962

Approved by:

M.S. Plesset 


\title{
EFFECTS OF THER MAL CONDUCTION \\ IN SONOLU MINESCENCE
}

\author{
Robert Hickling \\ California Institute of Technology \\ Pasadena, California
}

\begin{abstract}
Current experimental results indicate that sonoluminescence is largely thermal in origin, with the spectra showing a direct relation between luminous intensity and the temperatures generated inside the collapsing cavitation bubbles. In the present paper the strong dependence of the luminous intensity on the nature of the gas dissolved in the liquid is explained in terms of ther mal conduction. Provided the cavitation bubbles are sufficiently small, loss of heat from the bubble into the liquid can significantly reduce the temperatures attained during collapse, so that there is a consequent reduction in the luminous intensity. This process is demonstrated analytically by means of a numerical solution of the equations of motion of a gas inside a collapsing cavitation bubble. The agreement between the theory and the observed luminous intensities for different dissolved gases is good.
\end{abstract}




\section{Introduction}

Sonoluminescence is a weak emission of light which occurs when a liquid with dissolved gas is cavitated by a sound field. It is readily observed that the luminescence comes from the cavitation bubbles and also that it occurs in flashes with the same frequency as that of the sound. Although this effect has been known since the early 1930 's, it is only recently that quantitative results could be obtained using modern photomultiplier tubes. These results have been summarized and discussed by Jarman ${ }^{[1]}$ who concludes that they can best be explained on the assumption that sonoluminescence is largely thermal in origin. The cavitation bubbles collapse due to a return of positive pressure and compress the gas inside so that it becomes momentarily incandescent. Such high pressures were predicted by Rayleigh [2] a long time ago and arise because of the large inertial forces which are exerted when the liquid advances into the rarefied gaseous phase.

The spectra of sonoluminescence support this hypothesis. All distinctive band and line spectra appear to have been smeared out as though by very high pressures [3] to form a continuous distribution which usually stretches from the infra-red well into the ultra-violet. For -example the spectra of sonoluminescence for different gases dissolved in water appear to resemble that of a black body radiating between $6,000 \mathrm{~K}$,

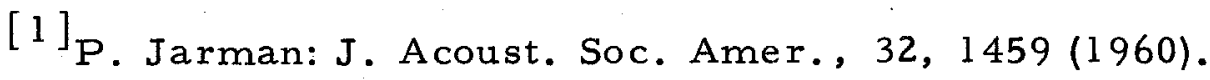

[2] Lord Rayleigh: Phil. Mag., 34, 94 (1917)

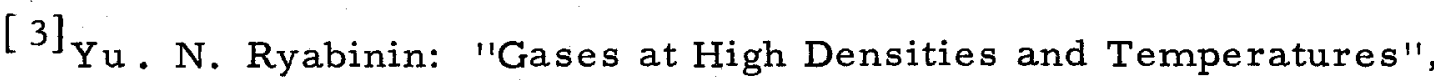
Pergamon Press (1961).
} 
TAB LE 1

$\begin{array}{lcccc}\text { Gas } & \begin{array}{c}\text { Relative Intensity } \\ \text { of Sonoluminescence }\end{array} & \begin{array}{c}\text { Thermal Conductivity } \\ \left(\mathrm{Cal} / \mathrm{cm} / \mathrm{sec} /{ }^{\circ} \mathrm{C}\right) \times 10^{3}\end{array} & \begin{array}{c}\text { Solubility in Water } \\ \text { Henry's Law Const. } \times 10^{-7}\end{array} & \begin{array}{r}\text { Molecula } \\ \text { Weight }\end{array} \\ \text { Helium } & 1 & 0.3365 & 10.90 & 4 \\ \text { Neon } & 18 & 0.1092 & 9.14 & 20.2 \\ \text { Argon } & 54 & 0.0385 & 2.58 & 39.9 \\ \text { Krypton } & 180 & 0.0212 & 1.52 & 83.8 \\ \text { Xenon } & 540 & 0.0124 & 0.742 & 131.3 \\ & & & & 2 \\ \text { Hydrogen } & - & 0.414 & 5.20 & 32 \\ \text { Oxygen } & 35 & 0.0583 & 2.95 & 28 \\ \text { Nitrogen } & 45 & 0.055 & 5.75 & 2\end{array}$


and $11,000^{\circ} \mathrm{K}^{[4],[5]}$. Although there seems to be no distinctive radiation lines or bands, the intensity of the luminescence has been found to depend in a striking, way on the nature of the dissolved gas [6], [7]. This is shown in Table 1 which lists the relative luminous intensities obtained by Prudhomme and Guilmart ${ }^{[6]}$ for water with different dissolved gases. The luminosity with helium was barely preceptible and with hydrogen could not be observed at all. The cause of this wide variation in intensity has not been very clearly understood, and the theory of the thermal origin of sonluminescence has been thought to be inadequate because it did not appear to account for it in a straightforward manner. However, such criticism is founded on the assumption that the cavitation bubbles collapse so rapidly that the gas is compressed adiabatically, and in the following analysis of the experiments of Prudhomme and Guilmart it will be shown that this is not the case.

Cavitation bubbles are of two main types, namely the vaporous and the gaseous [8],[9]. The former contain the liquid vapor principally

[4] P. Gunther, E.Heim and H.V. Borgstedt: Z. Electrochem. ,63,43(1959).

[5] D. Srinivasan: "The Sonoluminescence of Water". Ph.D. Thesis University of Missouri (1955).

[6] R. O. Prudhomme and Th. Guilmart: J. Chim. Phys., 54, 336(1957).

[7] P. Gunther, W. Zeil, U.Grisaw, E.Heim: Z.Electrochem., 61, 188(1957).

[8] F. G. Blake: Tech. Memo. No. 12, Acoustics Research Lab., Harvard University, Cambridge, Mass. (1949).

[9] M. D. Rosenberg: Tech. Memo. No. 26, Acoustics Research Lab., Harvard University, Cambridge, Mass. (1953). 
and have a comparatively short lifetime, while the latter contain a significant proportion of permanent gas in addition to the vapor and occur only when there is a sufficient gas content in the liquid. Since attempts to observe sonoluminescence with vaporous cavities have been unsuccessful [1], it is evident that it occurs preferentially with the gaseous type of bubble. Gaseous cavitation bubbles originate as small nuclei full of gas having radii of the order of $10^{-5} \mathrm{~cm}[8],[9]$. For pressure amplitudes larger than a certain threshold, such nuclei will accumulate dissolved gas from the liquid by means of a process described as rectified diffusion [10], in which there is a net inflow into the bubble during a complete cycle of os cillation of the bubble surface reacting under the applied sound field. The theory of this process $[10]$ shows that the rate of growth of such small nuclei will be relatively rapid, so that the bubbles quickly become large enough to allow the expansion and collapse typical of cavitation. Whether they grow much beyond this stage is uncertain. It is obvious from observation that they do not continue to grow indefinitely and must eventually break up into smaller bubbles which then continue the process.

The size of the cavitation bubbles is actually of critical importance. In their experiments Prudhomme and Guilmart made no direct observation of bubble size. However they did state that the excitation frequency was $960 \mathrm{kc} / \mathrm{sec}$ and the power of the transducer was 90 watts, and this information can be used as follows to estimate the maximum size of the

[10] D. Y. Hsieh and M. S. Plesset: J. Acoust. Soc. Amer., 33, 206 (1961). 
bubbles prior to collapse. The experiments were conducted under 1 atmos-

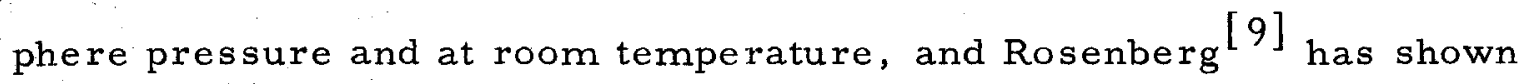
that for these conditions, the cavitation threshold for water saturated with gas occurs at a pressure amplitude of about 1.5 atmospheres. Once cavitation has started it can easily be maintained by amplitudes below this threshold. In the experiments of Prudhomme and Guilmart the acoustic waves were attenuated by being passed through a quartz window and it is apparent that, for a power of 90 watts, the pressure amplitude in the test vessel could not have been much more than a few atmospheres. Rayleigh's [2] formula for the collapse time of a spherical cavity is

$$
\tau \sim 0.9 R_{0}(\rho / p)^{\frac{1}{2}}
$$

where $R_{0}$ is the radius of the cavity prior to collapse and $p$ and $\rho$ are the ambient pressure and density in the surrounding liquid. For a pressure of only a few atmospheres in water, this relation becomes

$$
\tau \sim \frac{1}{2} 10^{-3} \mathrm{R}_{\mathrm{O}} \operatorname{secs}
$$

where $R_{o}$ is in centimeters. Since the acoustic wavelength is obviously much longer than bubble dimensions, this relation can be applied to the cavitation bubbles in the experiment. Now it is evident that these bubbles will only collapse effectively if the collapse time is less than a half cycle of the excitation, and for this to occur the initial radius $R_{0}$ would have to be less than $10^{-3} \mathrm{~cm}$. Other criteria, from the theory of os cillating bubbles, can be applied to support this estimate. According to the theory [10], the surface of a bubble is an oscillating pressure field becomes unstable when it exceeds a certain critical radius, which in the 
present case can be estimated to be about $10^{-3} \mathrm{~cm}$. Also the radius at which a bubble resonates under a $960 \mathrm{kc} / \mathrm{sec}$ excitation can be shown to be between $10^{-4}$ and $10^{-3} \mathrm{~cm}$. Finally Rosenberg ${ }^{[9]}$ has observed that under a $60 \mathrm{kc} / \mathrm{sec}$ excitation the maximum size of cavitation bubbles is about $10^{-2} \mathrm{~cm}$. It seems reasonable to expect therefore that, for a $960 \mathrm{kc} / \mathrm{sec}$ excitation, the maximum bubble radii should be of the order of $10^{-3} \mathrm{~cm}$.

It is to be expected then that the cavitation bubbles occurring in the experiments of Prudhomme and Guilmart range in size from about $10^{-5} \mathrm{~cm}$ to $10^{-3} \mathrm{~cm}$. where the bubbles are evolving from nuclei through the acquisition of dissolved gas from the water. No very precise description can be given of this evolution, however. In particular it is difficult to determine just how much gas and vapor will be present in the bubble when its surface goes into large scale oscillation. It obviously starts with exceedingly small amounts which increase by means of rectified diffusion from the dissolved gas in the liquid. In addition the gas content can be increased by the coalescence of several bubbles, since there are a very large number situated close together in a typical cavitation cloud. Thus it would appear that the gas content of a bubble could vary over quite a wide range. However it will be shown that the amount of gas necessary for effective luminescence is moderately small and restricted between fairly definite limits, so that only a certain proportion of the bubbles will be in the right condition. This agrees with observation since sonoluminescence would presumably be much brighter if all the bubbles in a cavitation cloud could radiate.

Radiation in the visible region of the spectrum occurs when a gas reaches temperatures in excess of about $1,000^{\circ} \mathrm{K}$. Prudhomme and 
Guilmart in fact measured their intensities in the ultra violet, with a photocell operating in the range $190 \mathrm{~m} \mu$ to $280 \mathrm{~m} \mu$ and having a sharp maximum sensitivity at $230 \mathrm{~m} \mu$. Hence the temperature attained by the gas would have to be of the order of $10,000^{\circ} \mathrm{K}^{[3]}$. This estimate is in agreement with the spectral distributions mentioned earlier [4],[5]. To reach such temperatures would require an adiabatic compression caused by a spherical bubble collapse of the order of $9 / 10$ of the initial radius, assuming ordinary temperatures initially. If the procress is not adiabatic but involves some loss of heat from the bubble, then the collapse will have to proceed further before the right temperatures are reached. In order to obtain such reductions in volume under a constant external pressure of a few atmospheres, it is necessary to limit the initial pressure of the gas to less than 0.1 atmospheres at ordinary temperatures. This estimate is obtained by using Gilmore's theory [11] of a collapsing spherical cavity, in which fairly accurate allowance is made for the compressibility of the liquid. This sets an upper limit on the amount of gas necessary for effective luminescence. A lower limit becomes apparent after the collapse process is considered in more detail.

The collapse of a bubble is generally considered to be quite rapid. However, the inertial forces in the liquid require time to build up and generate high velocities at the cavity wall. The presence of the gas inside does not affect the motion of the interface significantly until the very final stages when it eventually brings it to rest. It is possible to describe this

[11] F. R. Gilmore: Rept. No. 26-4, Hydrodynamics Laboratory, Calif. Inst. of Tech., Pasadena, Calif. (1952). 
behavior approximately, using Gilmore's theory ${ }^{[1]}$. For illustration a bubble having an initial radius $R_{0}=10^{-3} \mathrm{~cm}$ under a constant external pressure of 3 atmospheres is used. The collapse time $\tau$ is then about $\frac{1}{2} \mu \mathrm{sec}$. Inside the bubble there is assumed to be a uniform adiabatic gas of initial pressure $5 \times 10^{-2}$ atmospheres at ordinary temperatures.

Figure 1 shows how the radius $R$ of the bubble will vary with time $t$ for different $Y$, the ratio of the specific heats of the gas. The temperature of the gas goes as $\left(R_{0} / R\right)^{3(\gamma-1)}$ and the pressure as $\left(R_{0} / R\right)^{3}$. The motion is seen to be relatively independent of the presence of the gas up to $\mathrm{R} / \mathrm{R}_{\mathrm{O}} \sim 0.3$. At this stage the elapsed time $\mathrm{t}$ is about $0.97 \mathrm{~T}$ and the velocity has reached a value of about $7 \times 10^{3} \mathrm{~cm} / \mathrm{sec}$. i.e. it is still distinctly subsonic with respect to a gas at ordinary temperatures. The most significant point to notice from Fig. 1 however, is that, if some of the energy of the gas molecules is lost, or is absorbed within the molecule because of additional degrees of freedom, then the bubble attains lower final temperatures and collapses to smaller radii. This will profoundly affect the intensity of any resulting luminescence. Now air at ordinary temperatures and at 0.1 atmosphere pressure has a thermal diffusivity of about $3 \mathrm{~cm}^{2} / \mathrm{sec}$. Corresponding to a time of $\frac{1}{2} \mu \mathrm{sec}$, the thermal diffusion length is then about $10^{-3} \mathrm{~cm}$ i.e. equivalent to the dimensions of the bubble. Thus, since the surrounding water acts as an effective heat sink, it is obvious that significant heat losses from the gas inside the bubble can be expected during collapse, and that the luminous intensity will be affected correspondingly. If the initial pressure in the gas is much lower than 0.1 atmospheres say about $10^{-3}$ atmospheres or less, then the thermal diffusivity will be larger and the gas can be expected to remain in thermal equilibrium with 
the liquid at the bubble wall over most of the motion. This means that it will remain almost isothermal, and that only during the final stages will it approach adiabatic conditions. Hence the final temperatures will not be so high and the final radius will be smaller, so that not much luminescence can be expected as a consequence. This establishes a lower limit on the amount of gas necessary for effective luminescence. Actually for initial pressures of the order of $10^{-3}$ atmospheres it is inappropriate to consider thermal diffusion in the gas from a continuum standpoint, since the mean free paths are somewhat larger than the dimensions of the bubble. However it can be shown that there is sufficient time for the gas molecules to experience a large number of collisions with the bubble wall during most of the collapse, so that the conclusion is essentially the same.

Since condensation and evaporation rates are comparatively slow, water vapor will behave rather like a permanent gas and, since it is triatomic, it will effectively quench [3] the luminescence of other gases if it is present in any quantity. As has been pointed out earlier, no luminescence could be observed from vaporous cavitation in wate ${ }^{[1]}$, and it seems apparent from the experiments of Jarman ${ }^{[12]}$ that the presence of the liquid vapor does indeed diminish sonoluminescence. Also sonoluminescence appears quite distinctive for each dissolved gas and does not appear to arise from a mixture in which one constituent is always the same. For these reasons it is doubtful whether there can be a high proportion of vapor in the luminescing bubbles. As has already been pointed out, a typical cavitation cloud will contain bubbles whose gas and vapor content

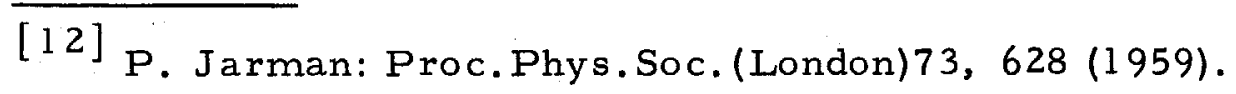


can be expected to vary over quite a wide range, and the luminescing bubbles will be those with the right amount of gas combined with only a small amount of vapor.

The fact that loss of heat from the gas inside the bubbles significantly affects the intensity of sonoluminescene, can be used to explain the wide variation in intensity which has been observed for different dis solved gases. This conclusion is supported by Table 1 where there is shown to be a clear inverse relation between the thermal conductivities under ordinary conditions [13] and the observed luminous intensities. It has also been suggested ${ }^{[5]}$ that the solubility of the gas is a contributory factor and that if there is more dissolved gas, then there will be more luminescence. This contention is only partially supported by Table 1 which lists the Henry's Law constant ${ }^{[14]}$ at ordinary temperatures. Also it is not in accord with the relative luminescences observed with different liquids [12]. The amount of dissolved gas can affect the number of the bubbles and, more significantly, their gas content. However these will also depend on the diffusivity of the gas in the liquid which appears [9] to exhibit an opposite trend to that of the solubility, i.e., the smaller molecules are more mobile and accurnulate in the bubbles more readily. Hence, provided there is sufficient gas present it is not certain that the luminous intensity should be related to the solubility. In comparison the modifying effect of heat loss from the bubbles is much more definite. According to

[13] Thorpe's Dictionary of Applied Chemistry, 4th Edit., Longmans Green and Co.

[14] Handbook of Chemistry and Physics, 41st Edit. Chemical Rubber Publishing Company. 
Table 1 , it is possible to obtain a relation between the observed luminous intensities and any parameter which is dependent on the molecular weight. However the thermal conductivity is itself dependent on the molecular weight, so that it would first be necessary to demonstrate that a parameter relates to a process which can clearly affect the luminescence, before attaching any particular significance to it.

It is evident that the luminous intensity will be dependent on the behavior of the gas during the final stages of collapse, and on the kinds of emission which can occur under such conditions. It has been suggested for instance by Jarman ${ }^{[1]}$ that microshocks may be responsible for part of the luminescence, and since the motion of the bubble wall can be supersonic at this point, this idea would seem to be quite plausible. However the final stages of the collapse and the resulting emission are outside the scope of this paper. It is sufficient for present purposes to point out that whatever takes place in the gas during these stages, will be strongly affected by the heat losses which can occur in the earlier motion.

Although it has been estimated that heat conduction does affect the behavior of the gas inside the bubble, it would be of some interest to examine the process in more detail. In particular it would be interesting to determine how the effect of thermal conduction varies with bubble size, and under what conditions the temperature of neon will become lower than that of nitrogen so as to accord with the relative luminescences given in Table 1. An analysis is therefore presented based on a simplified model of a collapsing spherical cavity in which the equations of motion of a the rmally conducting ideal gas are solved numerically up to the stage $R / R_{0}=0.3$. During this part of the motion, the bubble wall has a 
velocity which is much lower than the velocity of sound in the gas. Hence the acoustic waves generated by the motion of the wall have enough time to be reflected at the center of the cavity, thus avoiding the development of a pressure front. This makes the numerical solution relatively straightforward.

\section{Description of the Analytical Model}

A spherical cavity in an incompressible liquid contains a thermally conducting ideal gas with negligible quantities of the liquid vapor. It is assumed that both the gas and the liquid are non-viscous, and that prior to collapse they have the same uniform temperature $T_{0}$. It is also as sumed that during the collapse process, the temperature rise in the liquid at the cavity wall is negligible in comparison to the rise in temperature of the gas. This can be justified on the basis that the heat capacity of the liquid is much greater than that of the gas. Although the thermal conductivity of the liquid is generally about ten times greater than that of the gas, the thermal diffusivity of the gas will still be much greater than that of the liquid. Hence the thermal effects due to a transfer of heat out of the cavity will be confined to a comparatively narrow region of liquid next to the interface $[15]$. Since the temperature gradient in the liquid has its greatest value at the interface and since it will be about ten times smaller than the gradient in the gas, it follows that the temperature rise at the interface is small in comparison to the temperature rise in the interior of the gas. Hence the condition for the temperature on the boundary $T_{B}$ can be expressed

[15] M. S. Plesset and S. A. Zwick: J. Appl. Phys. 23, 95 (1952). 


$$
T_{B}=T_{O}
$$

In order to generate the collapse, the ambient pressure in the liquid is raiséd to a uniform value $p_{\infty}$ while the gas in the interior has the uniform value $p_{0}<p_{\infty}$. Initially the liquid and the gas are at rest. Allowing the pressure difference to take effect, the subsequent motion of the cavity wall is governed by the well-known relation for a collapsing spherical cavity $[16]$

$$
\frac{d U}{d t}=-\frac{1}{R}\left[\frac{p_{\infty}^{-p_{B}}}{\rho_{L}}+\frac{3}{2} U^{2}\right]
$$

where $p_{B}$ is the pressure exerted by the gas on the cavity wall, $U$ and $R$ are the velocity and radius of the wall and $\rho_{L}$ is the density of the liquid. At the center of the cavity the boundary conditions are

$$
\mathrm{u}=0 ; \quad \frac{\partial \mathrm{T}}{\partial \mathrm{r}}=0
$$

where $u$ is the velocity, $T$ the temperature and $r$ the radial coordinate. Since there is a moving boundary, it is necessary to express the equations of motion of the gas in Lagrangian form which for spherically symmetric motion are,

$$
\begin{aligned}
\rho r^{2} \frac{\partial r}{\partial y} & =1, \\
\frac{\partial u}{\partial t} & =-r^{2} \frac{\partial p}{\partial y},
\end{aligned}
$$

[16] M. S. Plesset: J. Appl. Mech., 16, 277 (1949). 


$$
\begin{aligned}
C_{v} \frac{\partial T}{\partial t} & =\frac{p}{\rho^{2}} \frac{\partial \rho}{\partial t}+k \frac{\partial}{\partial y}\left|\rho r^{4} \frac{\partial T}{\partial y}\right| \\
u & =\frac{\partial r}{\partial t},
\end{aligned}
$$

and the equation of state

$$
\frac{p}{\rho}=R_{g} T / M,
$$

where $p$ and $\rho$ are the density and pressure in the gas and $C_{v}$, and $k$ are the specific heat at constant volume and thermal conductivity. These last two quantities are as sumed to be constant throughout the motion - an assumption which is not valid when the gas reaches higher temperatures. $M$ is the molecular weight of the gas and $y$ is the Lagrangian independent variable referring to a particle of the gas. $R_{g}$ is the universal gas constant.

The above set of equations and boundary conditions were expressed in the form of finite difference relations as outlined in the Appendix, and solutions obtained by means of a high-speed digital computer. The initial conditions were chosen in accordance with those discussed in the previous section. The pressure $\mathrm{p}_{\infty}$ was made equal to 3 atmospheres and the initial temperature $\mathrm{T}_{\mathrm{o}}$ was $20^{\circ} \mathrm{C}$. The initial pressure $\mathrm{p}_{\mathrm{o}}$ inside the cavity was put equal to 0.075 atmospheres. This was chosen only slightly less than the up er limit mentioned in the introduction in order to keep the time of computation to a minimum. Moreover continuum theory is more certain to be applicable when the initial pressure has this value. The calculations were carried out for bubbles containing neon and nitrogen, of initial radii $10^{-1}, 10^{-2}, 10^{-3} \mathrm{~cm}$. 


\section{Discussion of the Results}

It is of interest to non-dimensionalize all the variables in the equations given in the previous section. Using the velocity of sound in the gas $c_{0}$ under the initial conditions, the initial radius $R_{0}$, the initial density and temperature of the gas $\rho_{0}$ and $T_{0}$, the dimensionless variables bècome

$$
\begin{gathered}
u^{\prime}=u / c_{0} ; \quad r^{\prime}=r / R_{0} ; \quad \rho^{\prime}=\rho / \rho_{0} ; \\
t^{\prime}=t c_{0} / R_{0} ; \quad T^{\prime}=T / T_{0} .
\end{gathered}
$$

Then since $c_{0}{ }^{2}=\gamma p_{0} / \rho_{0}=\gamma R_{g} T_{0} / M$ where $\gamma$ is the ratio of the specific heats, it follows from the equations that

$$
\begin{gathered}
\mathrm{p}^{\prime}=\mathrm{p} / \mathrm{\rho}_{\mathrm{o}} \mathrm{c}_{\mathrm{o}}^{2}=\mathrm{p} / \gamma \mathrm{p}_{\mathrm{o}}, \\
\mathrm{C}_{\mathrm{v}}{ }^{\prime}=\mathrm{C}_{\mathrm{v}} \mathrm{T}_{\mathrm{o}} / \mathrm{c}_{\mathrm{o}}{ }^{2}=M C_{\mathrm{v}} / \gamma \mathrm{R}_{\mathrm{g}},
\end{gathered}
$$

and

$$
k^{\prime}=k T_{o} / R_{0} \rho_{0} c_{0}^{3}=k\left(M T_{0}\right)^{\frac{1}{2}} / R_{o} p_{o} \gamma\left(R_{g}\right)^{\frac{1}{2}}
$$

When the variables appear in this form several features become apparent. If the thermal conductivity is negligible, Eq. (6) shows that the gas will behave in the usual adiabatic manner dependent principally upon whether the molecules are monatomic or diatomic. In this case the time will scale with the initial radius $R_{0}$, while the relative temperature pressure and velocity distributions will always be of the same magnitude regardless of the initial size of the cavity. On the other hand the effects of 
thermal conduction are inversely related to scale. When $R_{o}$ is large the behavior of the gas will be almost adiabatic, and when $R_{0}$ is small heat conduction will have a strong effect. The influence of heat conduction also depends on the initial pressure and to a lesser degree on the initial temperature.

If $\mathrm{p}_{0}<<\mathrm{p}_{\infty}$, it is to be expected that the behavior of the gas will have a negligible effect on the inertial force of the liquid throughout the major part of the collapse. Hence the total collapse time $\boldsymbol{T}$ is practically independent of the contents of the cavity, and will therefore be proportional to the initial radius $R_{0}$. The thermal diffusion length ${ }_{D}$ will then be proportional to $R_{0}^{\frac{1}{2}}$ and the ratio $\ell_{D} / R_{0}$ will vary as $R_{O}{ }^{-\frac{1}{2}}$. Thus the smaller bubbles will show increased effects of heat conduction even though their collapse times are smaller.

Another important feature is that the velocity of sound in the gas remains much higher than the velocity of the bubble wall throughout most of the motion. Under such conditions the pressure in the gas will remain comparitively uniform, because the effects of the disturbance created by the cavity wall have time to be distributed evenly throughout the gas.

These features are all clearly shown in the numerical solutions. When $R_{0}$ is large the solution is the same as for a uniform adiabatic gas, the differences being found to be within less than $1 \%$ at $R / R_{O}=0.3$. Figures $2-4$ give the solutions for $R_{0}=10^{-1}, 10^{-2}, 10^{-3} \mathrm{~cm}$. For $R_{0}=10^{-1}$ the thermal conductivity shows a perceptible effect, particularly when the temperature gradients become large. This increases when $R_{0}=10^{-2}$. When $R_{0}=10^{-3}$, heat conduction modifies the condition of the gas quite significantly, and it is seen that the temperature of 
neon falls slightly below that of nitrogen. As expected the pressure in the gas remains relatively uniform throughout the motion for all the cases considered. Figure 4 shows how this uniform pressure varies as a function of the bubble radius $R$, as compared to an adiabatic or an isothermal gas. For the $10^{-3} \mathrm{~cm}$ bubble the slope is seen to be almost along the isothermal initially but as the collapse accelerates it alters so that it parallels the adiabatic.

The solution for the $10^{-3}$ bubble represents the case closest to the conditions of the experiments of Prudhomme and Guilmart. However the average size of the cavitation bubble in these experiments is estimated to be somewhat smaller than $10^{-3} \mathrm{~cm}$, so that the effects of thermal conduction will be even more pronounced. Hence the temperature in the neon bubbles will fall more distinctly below that in the nitrogen bubbles. This would account for the difference in luminous intensity shown in Table 1 . 


\section{Appendix}

Initially the thermodynamic variables are uniform and have the values $\rho_{O}, T_{0}: P_{O}$ while the initial velocity in the gas is zero. The variable $y$ defined in equation (4) is taken to extend from 0 at the center to $\rho_{0} R_{0}^{3} / 3$ at the bubble wall and is divided into $n$ equal intervals $\Delta y . *$ The value of the radial coordinate $r$ at these intervals is then given by

$$
r_{j}{ }^{o}=\left(3 j \Delta y / \rho_{o}\right)^{\frac{1}{3}}: 0 \leqslant j \leqslant n
$$

where in the usual notation of a finite difference mesh the superscript $i$ refers to the number of intervals of time $\Delta t$ from the initial time $t=0$ and the subscript $j$ to the number of intervals of $\Delta y$ from the origin $y=0$. The thermodynamic variables were evaluated at the half intervals $\rho_{j}^{i}+\frac{1}{2}, T_{j}^{i}, \frac{1}{2}, p_{j}^{i}+\frac{1}{2}$ whereas the velocity $u_{j}^{i}$ and the radial coordinate $r_{j}$ were evaluated at the full intervals. In order to preserve accuracy at least in the initial stages, the temperature was divided into two parts so that

$$
T_{j}^{i}+\frac{i}{2}=T_{o}+T_{j}^{i}+\frac{i}{2}
$$

and the $\tau_{j}^{i}+\frac{1}{2}$ kept as the running variable. For the same reason equation (6) was modified so that the term $\frac{\partial \rho}{\partial t}$ was replaced by its equivalent $-p\left(\frac{2 u}{r}+p r^{2} \frac{\partial u}{\partial y}\right)$ derived from (4). Equations (4) - (8) were then expressed in finite difference form as follows

$$
\rho_{j+\frac{1}{2}}^{i+1}=3 \Delta y /\left(r_{j+1}^{i+1}-r_{j}^{i}+1\right)\left[\left(r_{j+1}^{i+1}\right)^{2}+r_{j+1}^{i+1} r_{j}^{i+1}+\left(r_{j}^{i+1}\right)^{2}\right]
$$




$$
\begin{aligned}
& u_{j}^{i}+1=u_{j}^{i}+\left(r_{j}^{i}\right)^{2} \Delta t\left(p_{j}^{i}+\frac{1}{2}-p_{j}^{i}-\frac{1}{2}\right) / \Delta y, \\
& \boldsymbol{\tau}_{j}^{i+\frac{1}{2}}=\tau_{j}^{i}+\frac{1}{2}-p_{j+\frac{1}{2}}^{i}\left[2\left(u_{j}^{i}+u_{j}^{i}+1\right) /\left(r_{j}^{i}+r_{j}^{i}+1\right)\right. \\
& \left.+\rho_{j}^{i}+\frac{1}{2}\left(r_{j}^{i}+r_{j}^{i}+1\right)^{2}\left(u_{j}^{i}+1-u_{j}^{i}\right) /(4 \Delta y)\right] /\left[c_{v} \rho_{j}^{i}+\frac{1}{2}\right] \\
& +k \Delta t\left[\left(\rho_{j}^{i}+\frac{3}{2}+\rho_{j}^{i}+\frac{1}{2}\right)\left(r_{j}^{i}+1\right)^{4}\left(\tau_{j}^{i}+\frac{1}{2}-\tau_{j}^{i}-\frac{1}{2}\right)\right. \\
& \left.-\left(\rho_{j}^{i}+\frac{1}{2}+\rho_{j}^{i}-\frac{1}{2}\right)\left(r_{j}^{i}\right)^{4}\left(\tau_{j}^{i}+\frac{1}{2}-\tau_{j}^{i}-\frac{1}{2}\right)\right] /\left[2 C_{V}(\Delta y)^{2}\right] \\
& r_{j}^{i}+1=r_{j}^{i}+u_{j}^{i} \Delta t \text {, } \\
& p_{j+\frac{1}{2}}^{i+1}=\rho_{j+\frac{1}{2}}^{i} \frac{R g}{M}\left(T_{o}+\tau_{j+\frac{1}{2}}^{i+1}\right) \text {. }
\end{aligned}
$$

Using these equations and the variables on the $i$ th row, a first estimate was obtained for the variables on the $(i+1)$ th row. In order to improve the accuracy of the derivatives with respect to the time $t$, one iteration was performed using this first estimate averaged with values on the $i$ th row. These averages were substituted in the appropriate locations within the above finite difference format and the new values which resulted were then carried on to the next stage. It was found necessary to make one exception in this process however. During the last stages of the calculation towards the end of the collapse, the procedure was found to be unstable unless the expressions in $u$ in equation (I.5) were replaced by $\left(u_{j}^{i}+1+u_{j}^{i}+1\right)$ and $\left(u_{j}^{i}+1-u_{j}^{i}\right)$ in the iteration. This change made no apparent difference in the accuracy of the results.

On the cavity wall, the velocity was found from equation (2) using 
the form

$$
u_{n}^{i+1}=u_{n}^{i}-\Delta t\left[\frac{\left(p_{\infty}-p_{R}^{i}\right)}{\rho_{L}}+\frac{3}{2} u_{n}^{i}\right] / r_{n}^{i}
$$

The pressure on the wall $\mathrm{p}_{\mathrm{R}}^{\mathrm{i}+1}$ was obtained by combining equations (2) and (5) to give

$$
\begin{aligned}
& p_{R}^{i+1}=\left[3 p_{n-\frac{1}{2}}^{i+1}-\frac{1}{3} p_{n-\frac{3}{2}}^{i+1}+\left\{\Delta y\left[p_{\infty}+\frac{3}{2}\left(u_{n}^{i+1}\right)^{2}\right]\right\} /\left(r_{n}^{i+1}\right)^{3}\right] / \\
& \left\{\frac{8}{3}+\left[\Delta y /\left(\mathbf{r}_{n}^{i}+1\right)^{3}\right]\right\}
\end{aligned}
$$

and the derivative $\partial \mathrm{T} / \partial \mathrm{y}$ on the cavity wall was found using the form

$$
\frac{\partial \mathrm{T}}{\partial \mathrm{y}} \sim\left(3 \tau_{\mathrm{n}-\frac{1}{2}}^{\mathrm{i}}-\frac{1}{3} \tau_{\mathrm{n}-\frac{3}{2}}^{\mathrm{i}}\right) / \Delta \mathrm{y}
$$

where the temperature on the cavity wall always has the same constant value $T_{0^{-}}$An iteration was also performed on these equations in the manner already described.

The above procedure was found to be quite stable provided [17]

$$
\Delta t<\alpha C_{v}(\Delta y)^{2} /\left[2 k \rho_{r}\left(r_{n}^{i}\right)^{4}\right]
$$

and

$$
\Delta t<\alpha_{2} \min _{j}\left(r_{j}^{i}+i-r_{j}^{i}\right) / c_{j}^{i}+\frac{1}{2}
$$

[17] R. D. Richtmeyer: "Difference Methods for Initial-Value Problems" Interscience Publishers Inc. New York, 1957, pp. 112, 202. 
where

$$
c_{j+\frac{1}{2}}^{i}=\left(\gamma p_{j+\frac{1}{2}}^{i} / \rho_{j+\frac{1}{2}}^{i}\right)^{\frac{1}{2}} .
$$

The most satisfactory value for the constants $\alpha_{1}$ and $\alpha_{2}$ was found to be 0.6. The first criterion was generally the predominant one. The number of points $n$ was varied from twenty to fifty. The twenty point solution showed a reasonable agreement with the fifty point solution, and the examples were calculated therefore for thirty points. The work was performed on an IBM 7090 and the longest example took about three hours. 


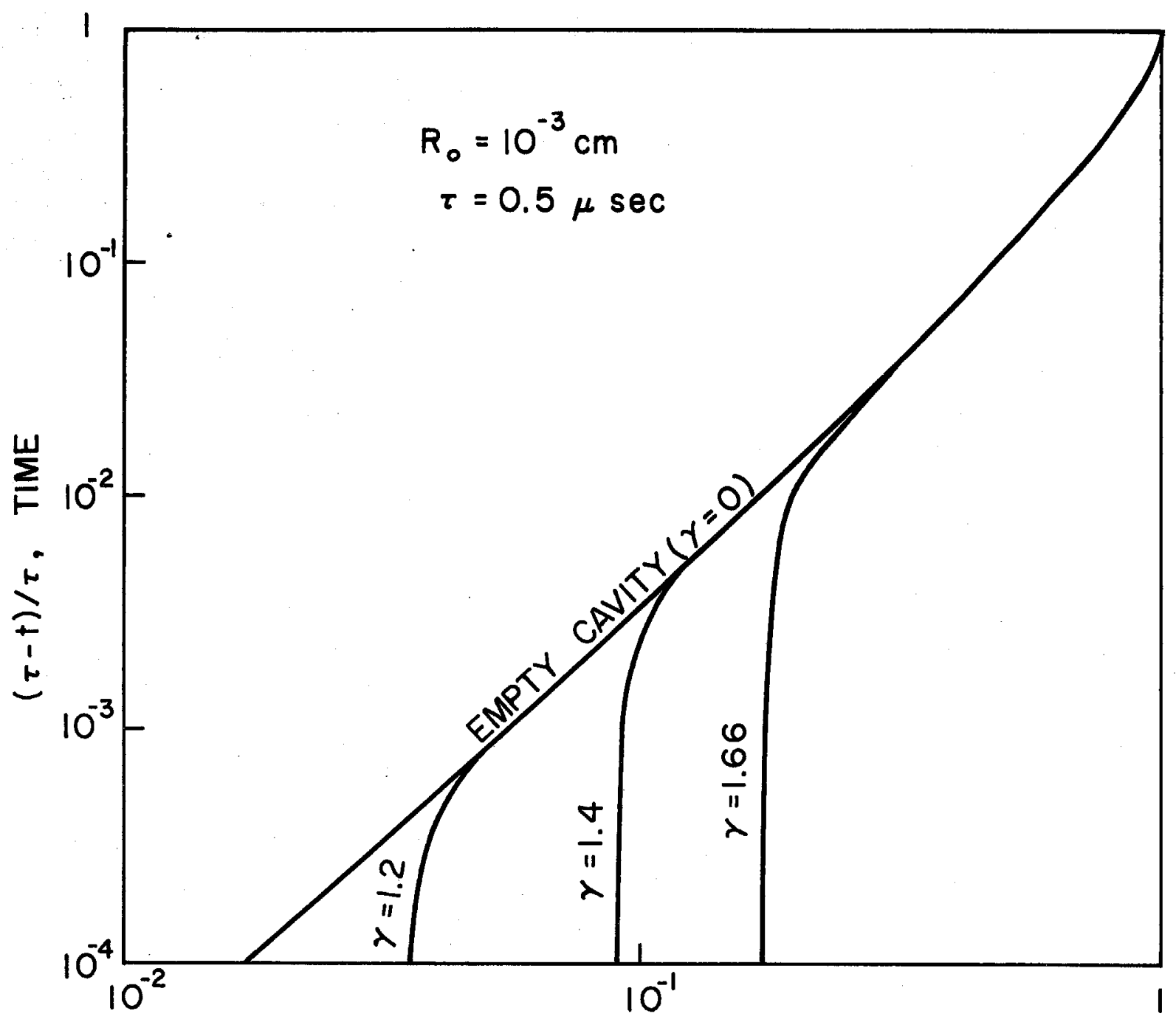

$R / R_{0}$, BUBBLE RADIUS

Figure 1. The variation with time of the radius of a spherical bubble containing a uniform adiabatic gas. The bubble is collapsing under a constant external pressure of 3 atmospheres and has an initial internal pressure of 0.05 atmospheres. 


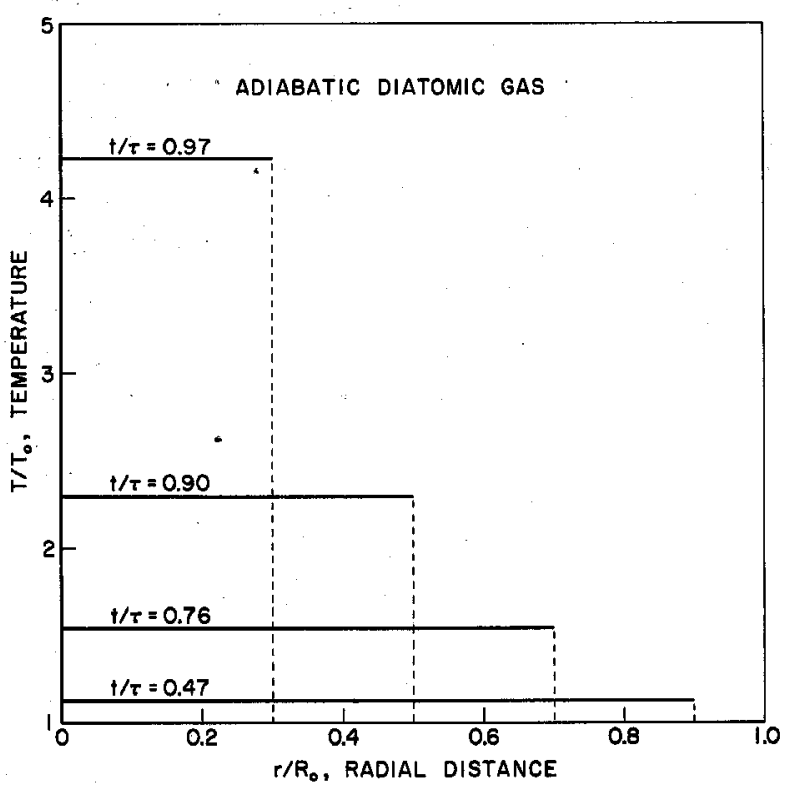

(a)

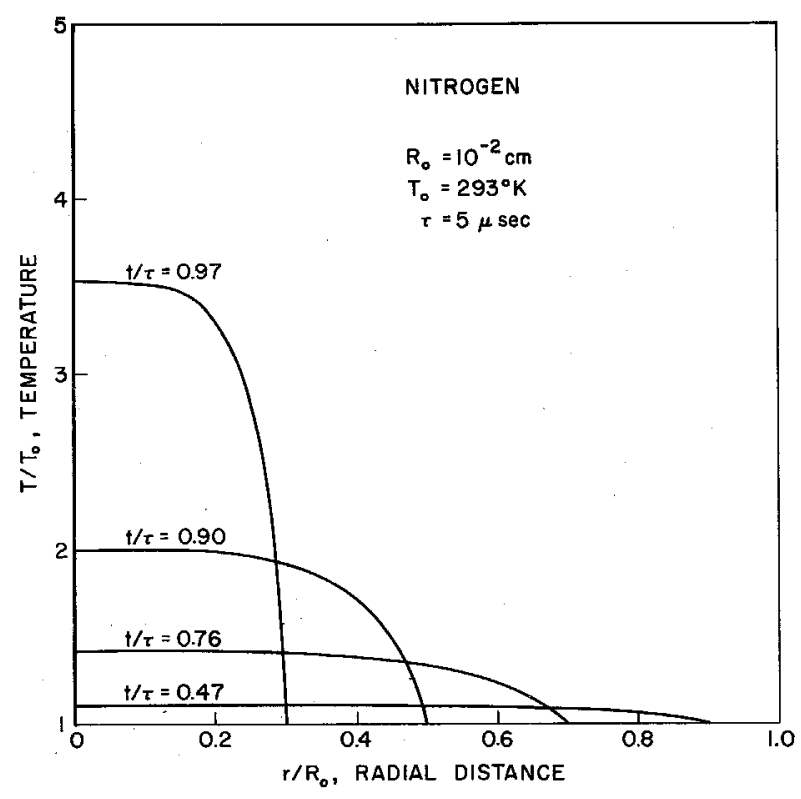

(c)

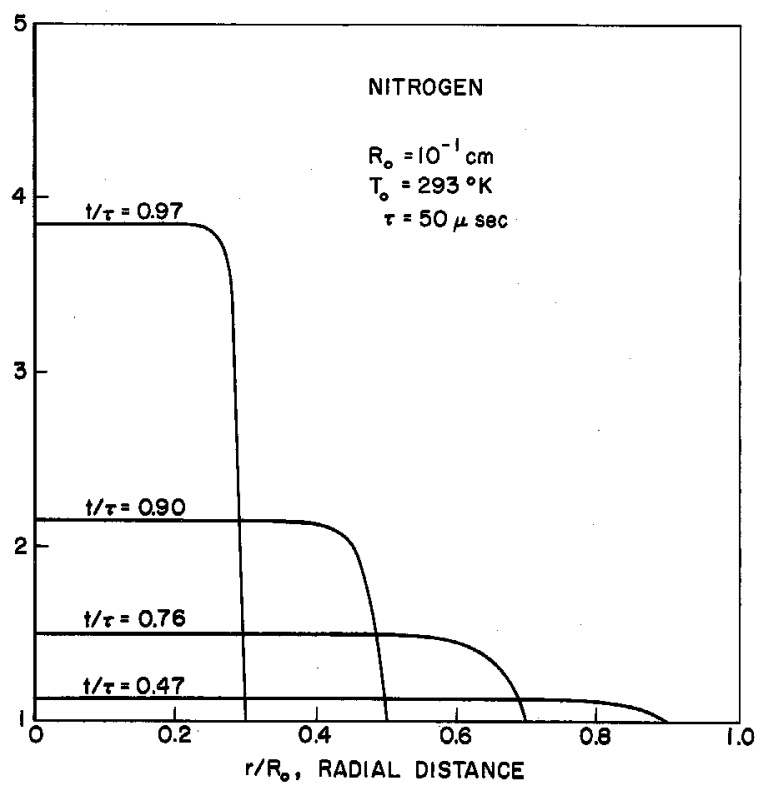

(b)

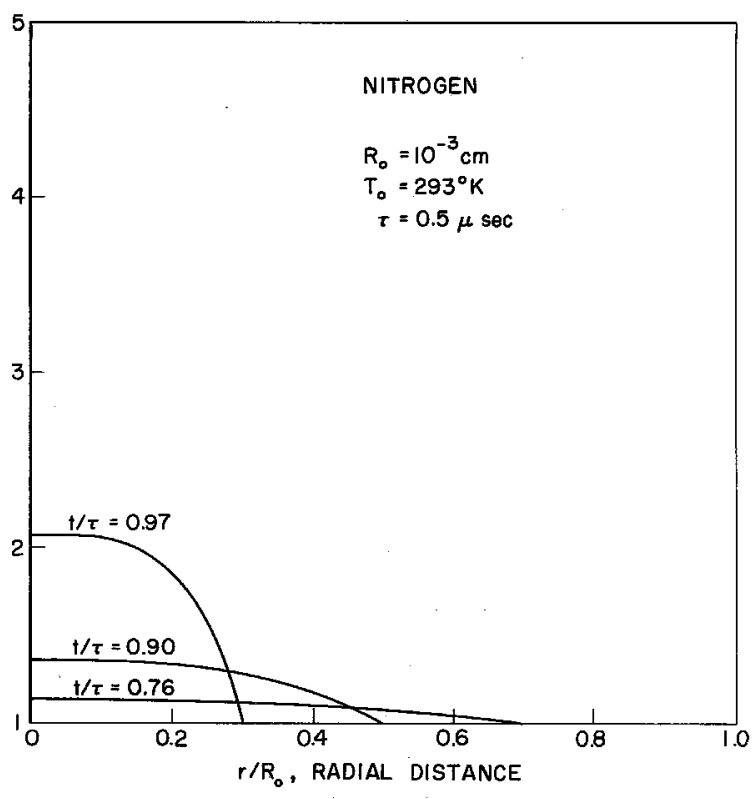

(d)

Figure 2. Temperature distributions inside a spherical bubble containing nitrogen at different stages of collapse, for different initial radii. The bubble is subjected to a constant external pressure of 3 atmospheres and has an initial internal pressure of 0.075 atmospheres. 


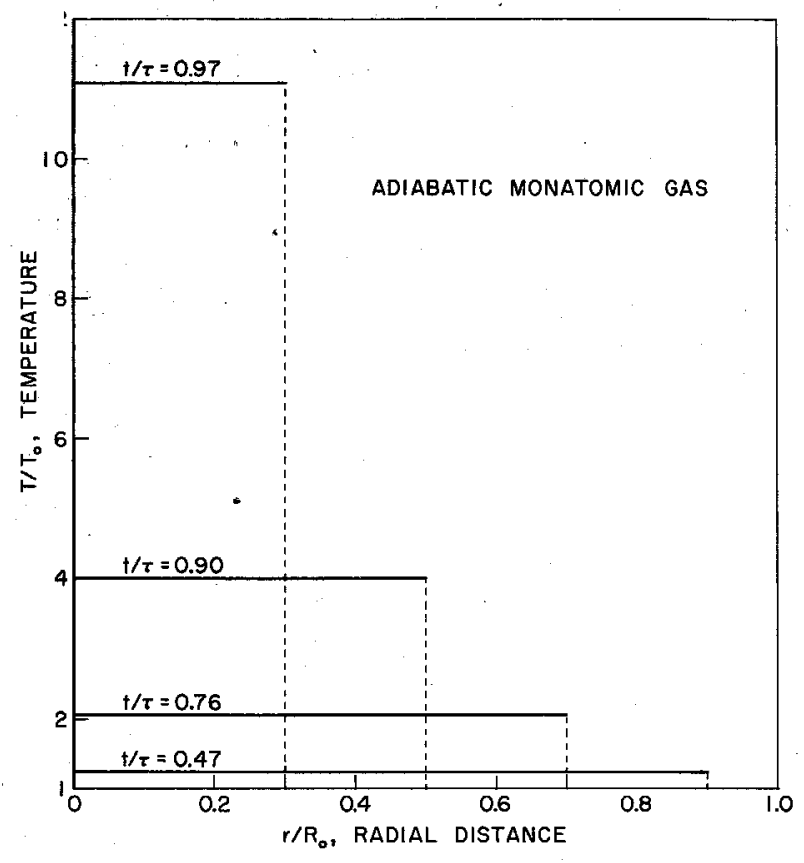

(a)

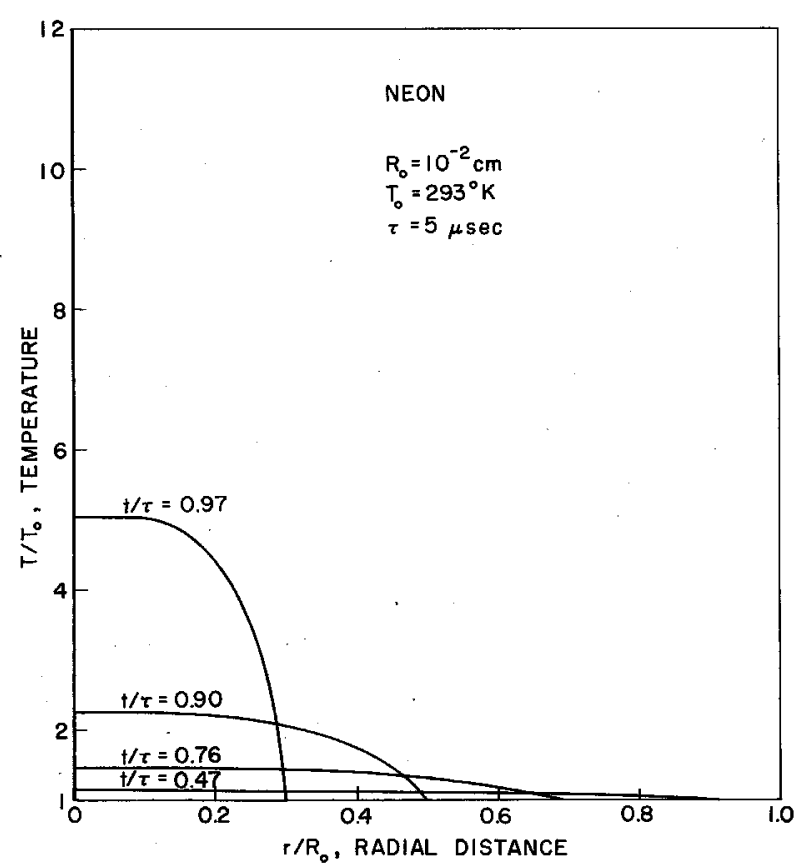

(c)

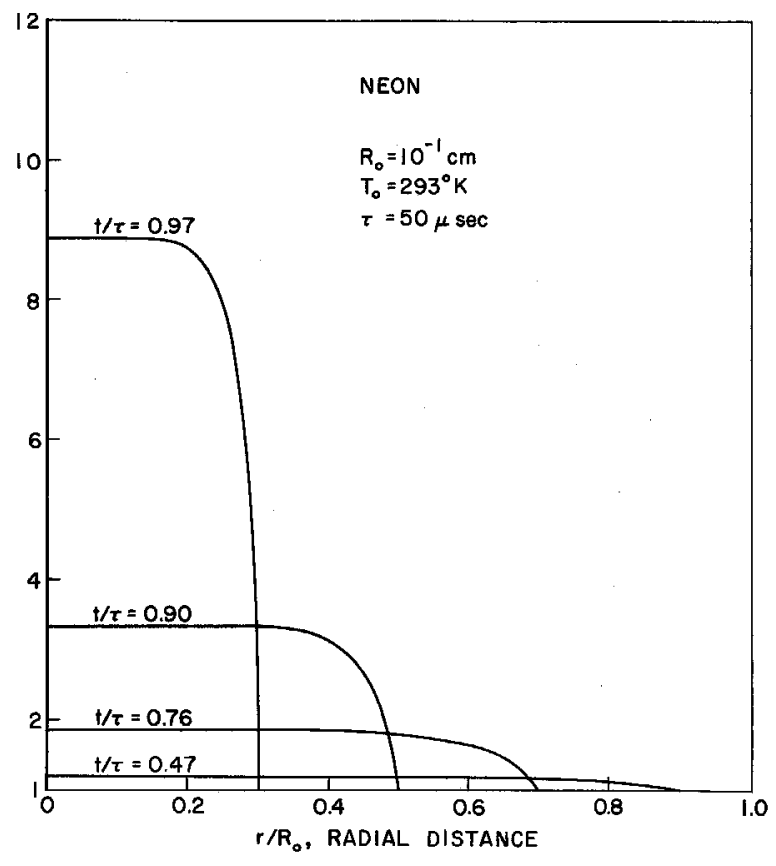

(b)

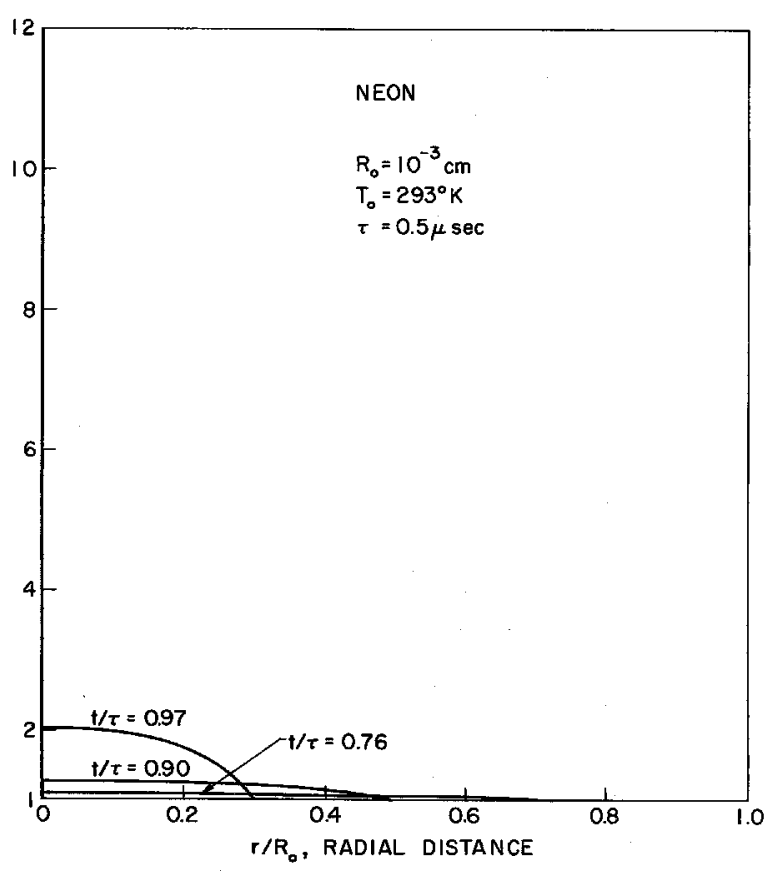

(d)

Figure 3. Temperature distributions inside a spherical bubble containing neon at different stages of collapse, for different initial radii. The bubble is subjected to a constant external pressure of 3 atmospheres and has an initial internal pressure of 0.075 atmospheres. 


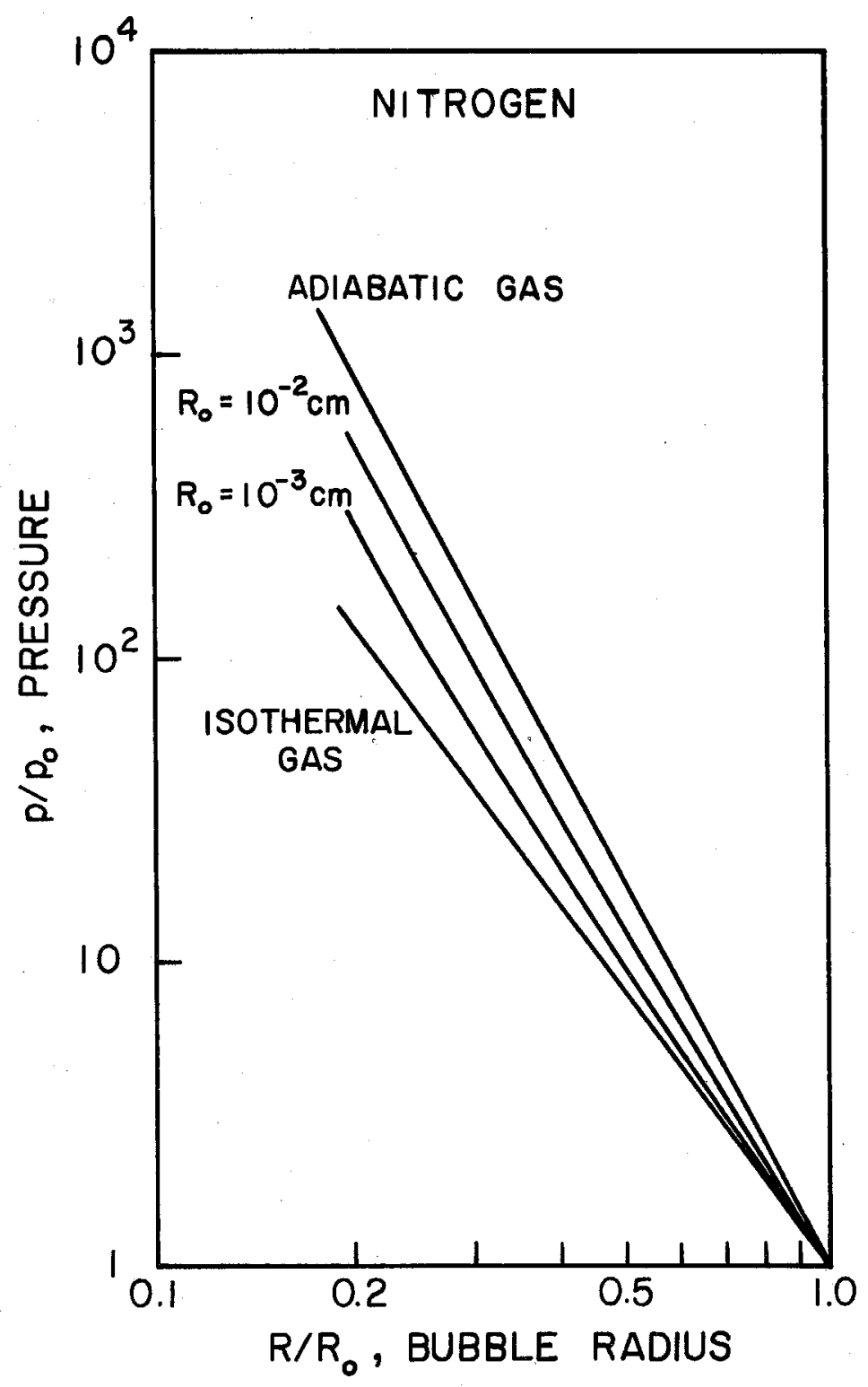

Figure 4. The variation of the uniform pressure inside a spherical bubble containing nitrogen, as a function of the bubble radius. The conditions are the same as those for Fig. 2 . 
DISTRIBUTION LIST FOR UNCLASSIFIED

REPORTS ON CAVITATION

Contract Nonr-220(28)

Single Copies Unless Otherwise Given

Chief of Naval Research Navy Department Washington 25, D. C. Attn: Code 438 (3)

Code 463

Commanding Officer Office of Naval Research Branch Office The John Crerar Library Chicago 1, Ill. Bldg。

Commanding Officer Office of Naval Research Branch Office 346 Broadway New York 13, N. Y.

Commanding Officer Office of Naval Research Branch Office 1030 E. Green Street Pasadena, California

Commanding Officer Office of Naval Research Navy 100, Fleet Post Office New York, N. Y.

Director

Naval Research Laboratory Washington 25, D.C. Attn: Code 2021

Chief, Bureau of Aeronautics Navy Department Washington 25, D. C. Attn: Research Division Aero and Hydro Branch (Code Ad-3) Appl. Mech. Branch (Code DE-3)

Commander Naval Ordnance Test Station Inyokern, China Lake, Calif. Attn: Technical Library
Commander

Naval Ordnance Test Station 3202 E。 Foothill Blvd.

Pasadena, California

Attn: Head, Underwater Ord. Head, Research Div. Pasadena Annex Library

Chief, Bureau of Weapons

Navy Department

Washington 25, D.C.

Attn: Asst. Chief for Research (Code Re)

Systems Director, Under water Ord. (Code Rexc) Armor, Bomb, Projectile, Rocket, Guided Missile Warhead and Ballistics Branch (Code Re 3)

Torpedo Branch (Code Re6)

Research and Components

Section (Code Re6a)

Mine Branch (Code Re7)

Chief, Bureau of Ships

Navy Department

Washington 25, D. C.

Attn: Research and Development (Code 300) Ship Design (Code 410) Preliminary Design and Ship Protection (Code 420) Scientific, Structural and Hydrodynamics (Code 442) Submarine (Code 525) Propellers and Shafting (Code 554)

Chief, Bureau of Yards and Docks, Navy Department

Washington 25, D.C.

Attn: Research Division

Commanding Officer and Dir. David Taylor Model Basin Washington 7, D.C.

Attn: Hydromechanics Lab. Seaworthiness and Fluid Dynamics Div. Library
Commanding Officer

Naval Ordnance Laboratory

White Oak, Maryland

Attn: Underwater Ordnance Dept.

Commanding Officer

Naval Underwater Ordnance Station

Newport, Rhode Island.

Dixector

Underwater Sound Laboratory

Fort Trumbull

New London, Conn.

Library

U. S. Naval Postgraduate School Monterey, California

Executive Secretary Research and Development Board

Department of Defense

The Pentagon

Washington $25, \mathrm{D}$. C.

Chairman

Underseas Warfare Committee

National Research Council

2101 Constitution Avenue

Washington $25, D . C$.

Dr. J. H. McMillen

National Science Foundation

$1520 \mathrm{H}$ Street, N. W.

Washington, D.C.

Director

National Bureau of Standards

Washington $25, D$. C.

Attn: Fluid Mech. Section

Dr. G. H. Keulegan

National Hydraulic Laboratory National Bureau of Standards Washington $25, \mathrm{D}$. C. 
Director of Research

National Aeronautics and Space Administration

1512 H Street, N. W.

Washington 25, D.C.

Director

Langley Aeronautical Lab.

National Aeronautics and Space Admin.

Langley Field, Virginia

Mr. J. B. Parkinson

Langley Aeronautical Lab.

National Aeronautics and

Space Administration

Langley Field, Virginia

\section{Commander}

Air Research and Development Command

P. O. Box 1395

Baltimore 18, Maryland

Attn: Fluid Mechanics Div.

Director

Waterways Experiment Sta.

Box 631

Vicksburg, Mississippi

Beach Erosion Board

U. S. Army Corps of Engineers

Washington 25, D. C.

Office of Ordnance Research

Department of the Army

Washington 25, D.C.

Office of the Chief of Engineers

Department of the Army

Gravelly Point

Washington 25, D.C.

Commissione $r$

Bureau of Reclamation

Washington 25, D.C.

Director

Oak Ridge National Lab.

P. O. Box P

Oak Ridge, Tenn.

Sandia Corporation Library

Sandia Base

Albuquerque, New Mexico
Professor Carl Eckart

Scripps Institute of

Oceanog raphy

La Jolla, California

Documents Service. Center

Armed Services Technical

Information Agency

Arlington Hall Station

Arlington 12, Virginia

$\mathrm{Mr}$. A. B. Needham

Research Direction

Minneapolis Mining

Research Center

Minneapolis 17, Minn.

Office of Technical Services

Department of Commerce

Washington 25, D.C.

Division of Applied Mathematics

Brown University

Providence 12, Rhode Island

California Institute of Technology

Pasadena, California

Attn: Professor A. J. Acosta

Professor A. Hollander

Professor C. B. Millikan

Professor M. S. Plesset

Professor V. A. Vanoni

Professor T. Y. Wu

University of California

Department of Engineering

Berkeley 4, California

Attn: Professor H. A. Einstein

Professor H. A. Schade

Professor J. V. Wehausen

Case Institute of Technology

Department of Mechanical Eng.

Cleveland, Ohio

Attn: Professor G. Kuerti

Cornell University

Grad. School of Aero. Eng.

Ithaca, New York

Attn: Prof. W. R. Sears

Harvard University

Cambridge 38, Mass.

Attn: G. Birkhoff, Dept.

of Mathematics

G. Carrier, Div. of Eng. and

Applied Physics
University of Illinois

Dept. of Theoretical and

Applied Mechanics

College of Engineering

Urbana, Illinois

Attn: Dr. J.M. Robertson

State University of Iowa

Iowa Institute of Hydraulic

Research

Iowa City, Iowa

Attn: Dr. Hunter Rouse

University of Maryland

Inst. for Fluid Dynamics and Applied Math.

College Park, Maryland

Attn: Prof. M.H. Martin Prof. J.R. Weske

Massachusetts Institute

of Technology

Cambridge 39, Mass.

Attn: Prof.W.M. Rohsenow Dept. Mech. Engr.

Prof. A. T. Ippen

Hydro. Lab.

Michigan State College Hydraulics Laboratory

East Lansing, Mich.

Attn: Prof. H. R. Henry

University of Michigan

Ann Arbor, Michigan

Attn: Director, Engineering Institute

Prof. V. L. Streeter

Civil Eng. Dept.

University of Minnesota

St. Anthony Falls Hyd. Lab. Minneapolis 14, Minn. Attn: Dr. L. G. Straub 
New York University

Inst. of Mathematical

Sciences

25 Waverly Place

New York 3, New York

Attn: Prof. R. Courant

University of Notre Dame

College of Engineering

Notre Dame, Indiana

Attn: Dean K.E. Schoenherr

Pennsylvania State University Ordnance Research Laboratory University Park, Pennsylvania Attn: Prof. G. F。 Wislicenus

Dr. J. Kotik

Technical Research Group

2 Aerial Way

Syosset, New York

Professor H. Cohen

IBM Research Center

P.O. Box 218

Yorktown Heights, New York

Stanford University

Stanford, California

Attn: Prof. D. Gilbarg, Dept. of Mathematics

Prof. L.I. Schoff, Dept. of Physics

Prof. J.K. Vennard, Dept. of Civil Eng.

Stevens Institute of Technology Experimental Towing Tank 711 Hudson Street

Hoboken, New Jersey

Worcester Polytechnic Institute Alden Hydraulic Laboratory Worcester, Mass.

Attn: Prof. J.L. Hooper

Dr. Th. von Karman

1051 S. Marengo Street

Pasadena, California

Aerojet General Corporation

6352 N. Irwindale Avenue

Azusa, California

Attn: Mr. C.A. Gongwer
Dr. J. J。 Stoker

New York University

Inst. of Mathematical Sciences

25 Waverly Place

New York 3, New York

Prof. C. C. Lin

Dept. of Mathematics

Massachusetts Inst. of Tech.

Cambridge 39, Mass.

Dr. Columbus Iselin

Woods Hole Oceanographic Inst.

Woods Hole, Mass.

Dr. A.B. Kinzel, Pres.

Union Carbide and Carbon

Research Laboratories, Inc.

$30 \mathrm{E}$. 42nd Street

New York, N. Y.

Dr. F. E. Fox

Catholic University

Washington 17, D.C.

Dr. Immanuel Estermann

Office of Naval Research

Code 419

Navy Department

Washington 25, D. C.

Goodyear Aircraft Corporation

Akron 15, Ohio

Attn: Security Officer

Dr. F. V. Hunt

Director, Acoustics Research

Laboratory

Harvard University

Cambridge, Mass.

Prof. Robert Leonard

Dept. of Physics

University of California at

Los Angeles

West Los Angeles, California

Technical Librarian

A VCO Manufacturing Corp.

2385 Revere Beach Parkway

Everett 49, Mass.

Dr. L. Landweber

Iowa Inst. of Hydraulic Research Bunkyo-ku, Tokyo, Japan

State University of Iowa

Iowa City, Iowa
Dr. M. L. Ghai

Supervisor

Heat Transfer/Fluid Mechanics

Rocket Engine-Applied

Research

Building 600

Aircraft Gas Turbine Div. General Electric Co.

Cincinnati 15, Ohio

Dr. W. W. Clauson

Rose Poly. Inst.

R. R. No. 5

Terre Haute, Indiana

Mr. Kurt Berman

Rocket Engine Section

Aircraft Gas Turbine

Development Dept.

Malta Test Station

Ballston Spa, New York

Officer in Charge

MWDP Contract

Supervisory Staff

SACLANT ASW Research

Center

APO 19, New York, N.Y.

Hydronautics, Inc.

200 Monroe Street

Rockville, Maryland

Attn: Mr. Phillip Eisenberg Mr。 Marshall P. Tulin

Commanding Officer and

Director

U.S. Naval Civil Eng, Lab.

Port Hueneme, California

Attn: Code L54

Dr. H. I. Uppal, Director

Irrigation and Power

Research Institute

Punjab, Amritsar, India

Prof. Taizo Hayashi,

Director

Hydraulics Laboratory

Chuo University

1, 1-chome, Koishikawa mati 
Prof. J. E. Cermak

Department of Civil Engineering

Colorado State University

Fort Collins, Colorado

Mr. John P. Herling

Order Librarian

Engineering Societies Library

United Engineering Trustees, Inc.

29 West 39th Street

New York 18, N. Y.

Mr. R. W. Kermeen

Dept. 8173, Bldg. 181N

Lockheed Missile and Space Company

P. O. Box 504

Sunnyvale, California

Material Laboratory Library

Building 291, Code 912B

New York Naval Shipyard

Brooklyn 1, New York

Professor Frederick G. Hammitt

Nuclear Engineering Department

The University of Michigan

Research Institute

Ann Arbor, Michigan

Commanding Officer

NROTC and Naval Administrative Unit

Massachusetts Institute of Technology

Cambridge 39, Mass.

Commanding Officer and Director U.S. Navy Mine Defense Laboratory

Panama City, Florida 